\title{
Pineal Apoplexy: Is it a Facilitator for the Development of Pineal Cysts?
}

\author{
P.D. McNeely, W.J. Howes, V. Mehta
}

\begin{abstract}
Background: The radiographic identification of pineal cysts has increased dramatically within the last two decades due to the advent of magnetic resonance imaging. Pineal cysts are often found incidentally with only a minority of these lesions ever becoming symptomatic and requiring treatment. Many theories attempting to explain the pathogenesis of these cysts exist. Methods: We describe a case of a 12-year-old girl who presents with a pineal hemorrhage of unknown etiology with associated hydrocephalus. Results: Her hydrocephalus was initially treated with an external ventricular drain followed by a third ventriculostomy. She had no evidence of elevated beta human chorionic gonadotropin or alpha-fetoprotein within the serum or cerebrospinal fluid. Follow-up imaging at seven weeks revealed resolution of her hemorrhage, however, there was development of a progressive cystic lesion within the pineal region. In order to make a definitive tissue diagnosis, a supracerebellar infratentorial surgical approach with complete resection was performed. During the resection, brownish fluid was aspirated from the cyst and the cyst wall was removed. The pathological diagnosis was a pineal cyst. Conclusions: Although cases have been described of pineal apoplexy with an underlying cyst, this case describes the development of a progressive pineal cyst secondary to a hemorrhage. This case demonstrates that pineal hemorrhage may be a promotor for the development or progression of pineal cysts.
\end{abstract}

RÉSUMÉ: L’apoplexie pinéale, un facilitateur du développement de kystes de la glande pinéale? Contexte: L'identification radiologique de kystes pinéaux a augmenté de façon dramatique dans les deux dernières décennies grâce à la disponibilité de l'imagerie par résonance magnétique. Les kystes pinéaux sont souvent une découverte fortuite. Cependant, seulement une minorité de ces lésions devient symptomatique et nécessite un traitement. Plusieurs théories tentent d'expliquer la pathogenèse de ces kystes. Méthodes: Nous décrivons le cas d'une jeune fille de 12 ans qui a consulté pour une hémorragie de la glande pinéale d'étiologie inconnue associée à une hydrocéphalie. Résultats: Son hydrocéphalie a été traitée initialement au moyen d'un drain ventriculaire, puis par une ventriculostomie du troisième ventricule. Elle ne présentait pas d'élévation de la bêta-gonadotropine chorionique humaine ou de l'alpha-foetoprotéine dans le sérum ou le liquide céphalo-rachidien. L'imagerie en série sur une période de sept semaines a montré la résorption de l'hémorragie accompagnée cependant du développement d'une lésion kystique progressive dans la région de la pinéale. Afin d'établir un diagnostic tissulaire définitif, une résection complète a été effectuée par une approche chirurgicale sous-tentorielle. Pendant la résection, un liquide brunâtre a été aspiré du kyste et la paroi du kyste a été enlevée. Le diagnostic anatomopathologique a été celui de kyste pinéal. Conclusions: Bien que des cas d'apoplexie de la glande pinéale avec kyste sous-jacent aient été décrits, ce cas illustre le développement progressif d'un kyste secondaire à une hémorragie. Ce cas démontre que l'hémorragie de la pinéale peut promouvoir le développement ou la progression de kystes de la glande pinéale.

Can. J. Neurol. Sci. 2003; 30: 67-71

Pineal apoplexy may lead to the development of ill-defined symptoms. ${ }^{1}$ Cases of pineal apoplexy have been reported in the literature over the past 25 years with patients harboring a diverse group of underlying pathological lesions. ${ }^{1-9}$

The premise that pineal apoplexy may more often occur in association with an underlying malignant lesion as opposed to a benign lesion is not supported in the literature. Hemorrhage within a pineal cyst, leading to an acutely declining neurological state has been reported in patients with and without anticoagulant therapy. ${ }^{1,4}$

Pineal cysts are benign lesions found incidentally in $25-40 \%$ of all autopsies. ${ }^{10-12}$ Pineal cysts have recently gained more attention because of an increased frequency of diagnosis secondary to magnetic resonance imaging. Incidence rates in the

From the IWK Children's Hospital, Dalhousie University, Division of Neurosurgery, Halifax, Nova Scotia (PDM, WJH); Stollery Children's Hospital, University of Alberta, Division of Neurosurgery, Edmonton, Alberta (VM), Canada. ReCeived February 4, 2002. AcCePted In Final fORM August 12, 2002. Reprint requests to: Vivek Mehta, 2D1.02 - Mackenzie Health Sciences Center, 8440112th Street - University Hospital, University of Alberta, Division of Neurosurgery, Edmonton, Alberta, Canada T6G 2B7 
general population are in the 1.5 to $4.3 \%$ range, with a higher rate of $5.8 \%$ being demonstrated among young females between 21 and 30 years of age. ${ }^{13-18}$

The discrepancy between the imaging frequency of these cysts and the number actually ever requiring treatment illustrates their benign nature. It is unusual for these cysts to enlarge to a degree such that they cause major symptoms. When symptoms do occur they are a function of either hydrocephalus secondary

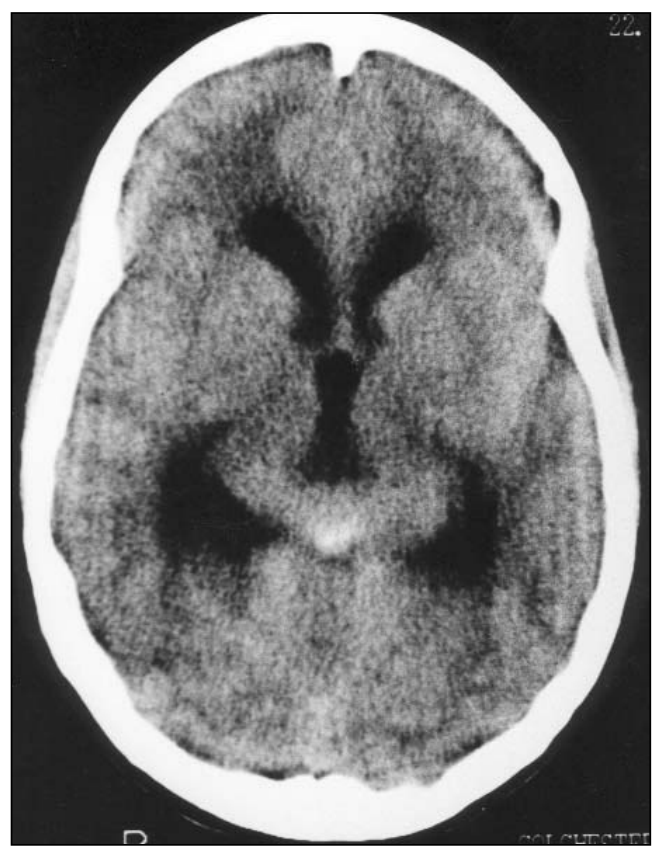

Figure 1: Axial unenhanced CT scan revealing a 10 by $14 \mathrm{~mm}$ hyperdensity in the pineal region.

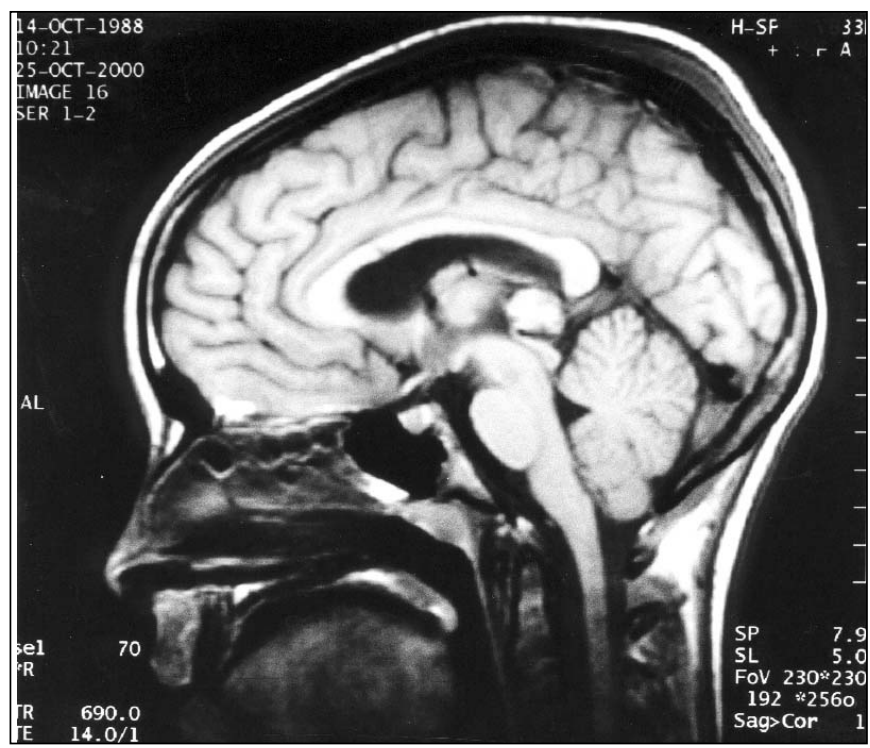

Figure 2a: Sagittal unenhanced T1-weighted magnetic resonance image revealing a 14 by $12 \mathrm{~mm}$ lesion with a signal consistent with recent hemorrhage. to aqueductal compromise or ocular findings secondary to a dorsal midbrain syndrome.

The underlying pathogenesis responsible for the development of these pineal cysts remains controversial. Theories for cyst development have included the persistence of the cavum pineale, invagination of the pineal gland, ependymal invasion of glial lacunae and the coalescence of smaller cysts. ${ }^{10,11,17,19,20}$

\section{Case Report}

A previously healthy, 12-year-old girl presented with a six-day history of headaches, nausea, vomiting and syncopal episodes. Computed tomography performed by her referring hospital revealed a 10 by 14 millimeter hyperdense pineal region mass with associated noncommunicating hydrocephalus (Figure 1). On arrival at our emergency department she was unresponsive secondary to acute hydrocephalus. Her neurological exam dramatically responded after endotracheal intubation and placement of an external ventricular drain. Both serum and cerebrospinal fluid levels of alphafeta-protein and human chorionic-gonadotropin levels were within normal limits. Magnetic resonance imaging (MRI) demonstrated a hemorrhagic lesion within the pineal gland (Figures 2a-b).

Her hydrocephalus was definitively treated with an endoscopic third ventriculostomy. She recovered completely and we elected to follow her clinically and radiographically. Subsequent MRI imaging seven weeks later, demonstrated an increasing lesion within the pineal region with resolution of the blood products. (Figure 3a-3b) The lesion was largely cystic and demonstrated cyst wall enhancement on gadolinium infused magnetic resonance imaging.

Due to the increasing size of the lesion we felt a surgical biopsy, in order to gain a definitive pathological diagnosis, was indicated. As the child was asymptomatic and her hydrocephalus had already been treated with an endoscopic third ventriculostomy, one may have also chosen a more conservative approach of careful observation.

A supracerebellar, infratentorial surgical approach was adopted with

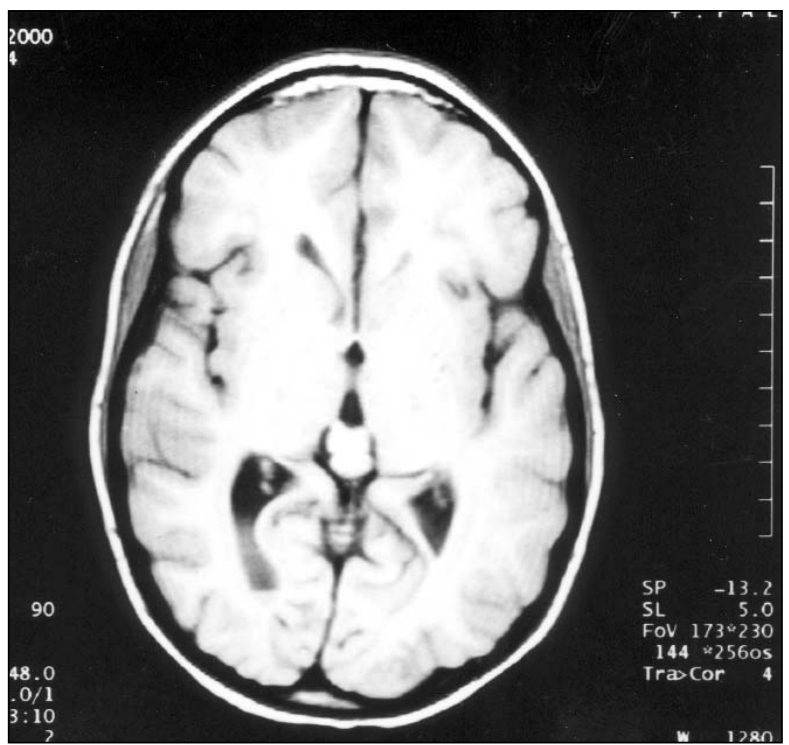

Figure 2b: Axial T1-weighted magnetic resonance image revealing a hyperintense lesion in the pineal region. 


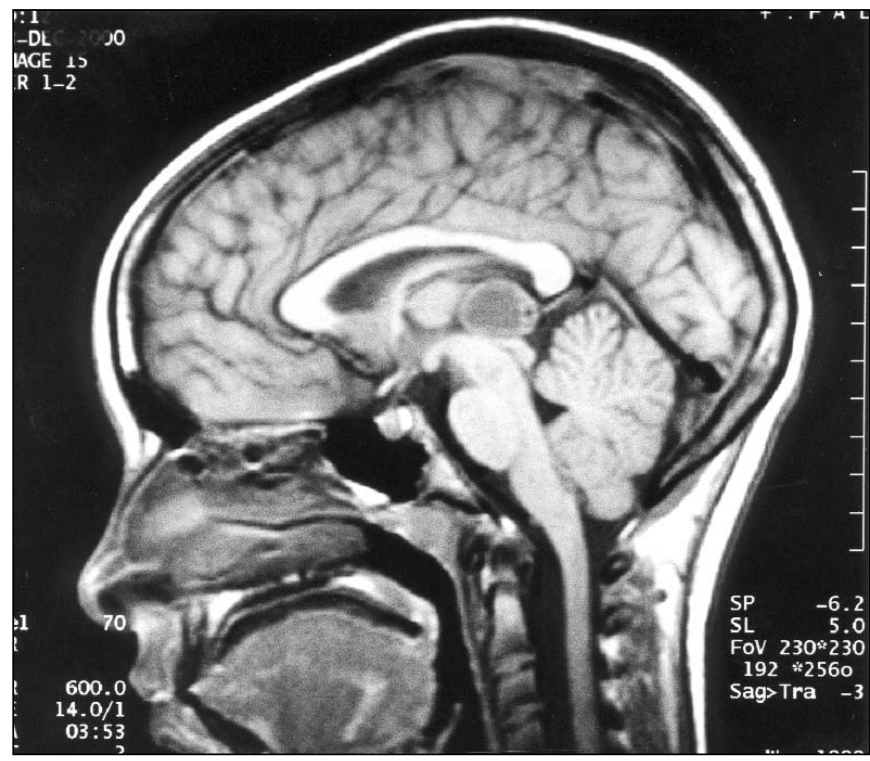

Figure 3a: Seven weeks after the initial hemorrhage, a sagittal T1weighted magnetic resonance image, demonstrating a larger cystic lesion extending into the third ventricle with compression of the cerebral aqueduct.

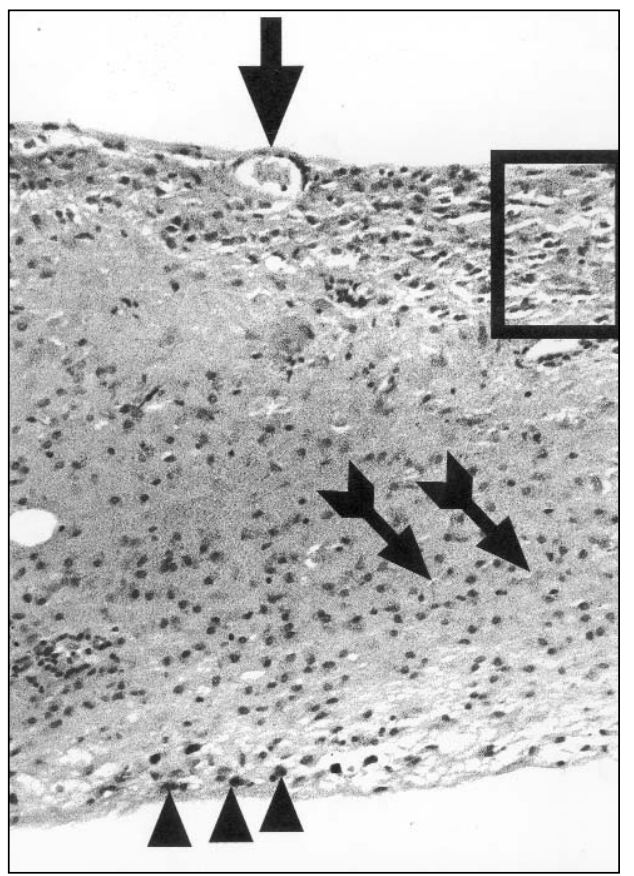

Figure 4: Histological examination of the specimen revealed three distinct layers. The inner layer was compromised of reactive astrocytes with abundant Rosenthal fibre formation and frequent granular bodies. Also present were occasional hemosiderin containing macrophages at the innermost aspect. The next layer was comprised of compressed normal pineal gland with the outermost layer consisting of a very attenuated fibrous connective tissue investment.

The three arrowheads at the inner aspect point to hemosiderin macrophages. The arrows within the wall point to representative Rosenthal fibres in the astroglial portion of the cyst wall. The box encloses a portion of the compressed normal pineal gland. The large arrow points to a blood vessel in the outer fibrous connective tissue layer. (H\&E stained section $x 200)$

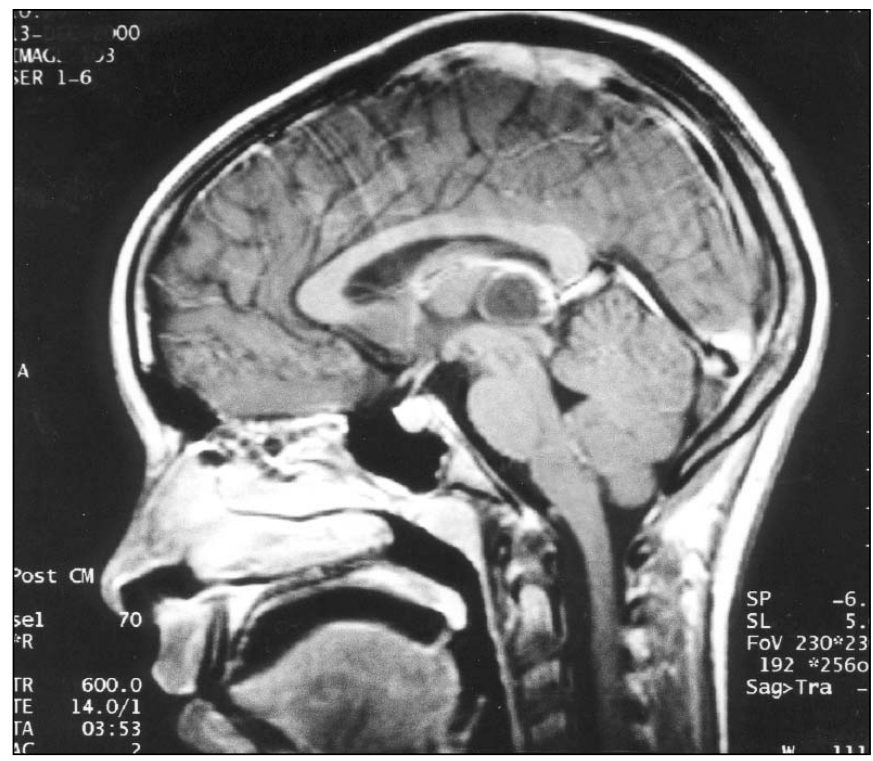

Figure 3b: Seven weeks after the initial hemorrhage, a sagittal gadolinium enhanced T1-weighted magnetic resonance image demonstrating some enhancement of the posterior and superior wall of the cyst.

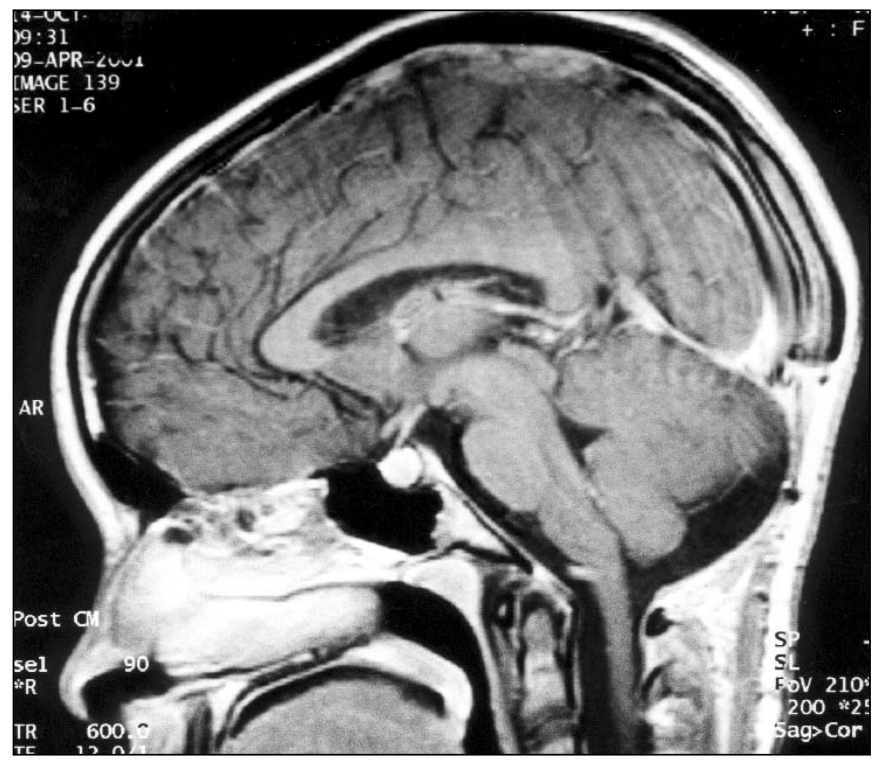

Figure 5: A sagittal gadolinium enhanced magnetic resonance image, three months postoperatively demonstrating no residual cyst. 
the patient placed in the concorde position. The lesion was well-defined and consisted of a tan coloured cyst capsule containing yellowishbrownish type fluid. The final histological diagnosis was of a pineal cyst with evidence of recent hemorrhage (Figure 4). She was discharged home neurologically intact, with postoperative magnetic resonance imaging at three months demonstrating complete removal of the lesion (Figure 5).

\section{Discussion}

Symptomatic pineal apoplexy is a rare occurrence, first being described within the neurosurgical literature by Apuzzo et $\mathrm{al}^{1}$ in 1976. This case was of a 56-year-old man on anticoagulants who presented with headache, lethargy, and a gaze palsy due to the hemorrhage into a pineal cyst.

The first craniotomy for a pineal cyst was performed in 1914, and since that time less than one hundred cases have been reported. 1,3-6,13,17-19,21-35 The majority of these cases represent cysts that presented with mass effect on the dorsal midbrain leading to visual complaints or symptoms secondary to obstruction of cerebrospinal fluid pathways.

Symptomatic pineal cysts can occur in all age groups and may be more common in females. ${ }^{6,9,22}$ Pineal cysts are relatively common and have been found with increasing frequency in vivo with the advent of modern imaging techniques. ${ }^{14-16}$ In spite of the common occurrence of pineal cysts, their underlying pathogenesis is not completely understood. Some authors have suggested that these lesions result from minor imperfections in the gland's normal embryogenesis. ${ }^{5}$ Other theories concerning their formation include normal involution of the pineal gland, ischemic glial degeneration with secondary cyst formation, and ependymal invasion of glial lacunae. ${ }^{12,21}$

It has also been postulated that larger pineal cysts may actually represent a coalescence of smaller pineal cysts. ${ }^{19}$ This coalescence explanation seems inadequate based on the discrepancy between the rarity of large pineal cysts and the significant number of smaller cysts found in autopsy series. ${ }^{12}$ This theory is further flawed by the predominance of young patients within the symptomatic pineal cyst population. ${ }^{21}$ Various reports have also demonstrated women first becoming symptomatic with their pineal cysts during pregnancy. ${ }^{21,35}$ This information, coupled with the higher rates of cyst formation in younger females, has led many to believe that hormonal influences associated with pregnancy or the menstrual cycle may play a role in the pathogenesis of these cysts. Other theories for the growth of large pineal cysts have included cerebrospinal fluid that flows through a direct connection with the third ventricle. ${ }^{35}$

With the advent of magnetic resonance imaging, these lesions are now often identified incidentally and neurosurgical opinion is obtained. Pineal cysts greater than 5 millimeters in size have been identified radiographically in $1-4 \%$ of the general population with rates being slightly higher in the young female population. ${ }^{13-18}$ Magnetic resonance imaging reveal these pineal cysts to be slightly higher intensity when compared to the cerebrospinal fluid on T1-weighted and T2-weighted images. On proton-density imaging these cysts were often much more intense than the cerebrospinal fluid. A thin wall can often be appreciated on T1-weighted images with rim enhancement when the patient receives gadolinium. ${ }^{17}$
Our report describes a case of pineal apoplexy resulting in an expanding pineal cyst. It is unclear in our case, if the initial hemorrhage took place within a small pineal cyst that subsequently enlarged or within the stroma of the pineal gland itself. Evidence of previous hemorrhages within pineal cysts is supported by xanthochromia and hemosiderin laden macrophages within specimens from symptomatic patients. ${ }^{6}$ It is possible that microhemorrhages are responsible for the expansion of pineal cysts. In a series by Fain et $\mathrm{al}^{22}$ histological evidence of prior hemorrhage in the form of hemosiderin deposits within the glial layer in the predominantly perivascular distribution was found in eight of 24 cases. We may also speculate, that in our case, simple osmotic forces may have been responsible for an increase in the lesion size.

Our case demonstrates how a pineal hemorrhage may be an instigator for the development of a pineal cyst within a short period. Knowledge of this mechanism of cyst growth is helpful to surgeons when approaching patients with lesions in the pineal region. Surgery done only for the sake of defining the pathological nature of this type of lesion should be avoided. The theory of pineal hemorrhage leading to the development of an expanding pineal cyst is supported by this case, although other models of pathogenesis may still exist.

\section{ACKNOWLEDGEMENTS}

We thank Dr. R.O. Holness, Dr. L. Resch and the IWK audiovisual department for assistance in the preparation of this article.

\section{REFERENCES}

1. Apuzzo MLJ, Davey LM, Manuelidis EE. Pineal apoplexy associated with anticoagulant therapy. Case report. J Neurosurg 1976; 45: 223-226.

2. Steinbok P, Dolman CL, Kaan K. Pineocytomas presenting as subarachnoid hemorrhage. J Neurosurg 1977; 47: 776-780.

3. Burres KP, Hamiltoj RD. Pineal apoplexy. Neurosurgery 1979; 4: 264-268.

4. Higashi K, Katayama S, Orita T. Pineal apoplexy. J Neurol Neurosurg Psychiatry 1979; 42: 1050-1053.

5. Richardson JK, Hirsch CS. Sudden, unexpected death due to "pineal apoplexy". Am J Forensic Med Pathol 1986; 7: 64-68.

6. Wisoff JH, Epstein F. Surgical management of symptomatic pineal cysts. J Neurosurg 1992; 77: 896-900.

7. Koenigsberg RA, Faro S, Marino R, Turz A, Goldman W. Imaging of pineal apoplexy. Clin Imaging 1996; 20: 91-94.

8. Swaroop GR, Whittle IR. Pineal apoplexy: an occurrence with no diagnostic clinicopathological features. Br J Neurosurg 1998; 12: 274-276.

9. Mukherjee KK, Banerji D, Sharma R. Pineal cyst presenting with intracystic and subarachnoid haemorrhage: report of a case and review of the literature. Br J Neurosurg 1999; 13: 189-192.

10. Cooper ERA. The human pineal gland and pineal cysts. J Anat 1932; 67: 28-46.

11. Tapp E, Huxley H. The histological appearance of the human pineal gland from puberty to old age. J Pathol 1972; 108: 137-144.

12. Hasegawa A, Ohtsubo K, Mori W. Pineal gland in old age: quantitative and qualitative morphological study of 168 human autopsy cases. Brain Res 1987; 409: 343-349.

13. Osborn RE, Deen HG, Kerber CW, Glass RF. A case of hemorrhagic pineal cyst: MR/CT correlation. Neuroradiology 1989; 31: 187189.

14. Marmourian AC, Towfighi J. Pineal cysts: MR imaging. AJNR 1986; 7: 1081-1086.

15. Lee DH, Norman D, Newton TH. MR imaging of pineal cysts. J Comput Assit Tomogr 1987; 11: 586-590. 
16. Lum GB, Williams JP, Machen BC, Akkaraju V. Benign cystic pineal lesions by magnetic resonance imaging. J Comput Tomogr 1987; 11: 228-235.

17. Sandhu JS, McLaughlin JR, Gomez CR. Characteristics of incidental pineal cysts on magnetic resonance imaging. Neurosurgery 1989; 25(4): 636-640.

18. Sawamura Y, Ikeda J, Ozawa M, et al. Magnetic resonance images reveal a high incidence of asymptomatic pineal cysts in young women. Neurosurgery 1995; 37(1): 11-16.

19. Carr JL. Cystic hydrops of the pineal gland. With a report of six cases. J Nerv Ment Dis 1994; 99: 552-572.

20. Kappers JA. Epiphysis. In: Crosby EC, Humphrey T, Lauer EW, eds. Correlative Anatomy of the Nervous System. New York: Macmillan, 1962: 268-271.

21. Klein P, Rubinstein LJ. Benign glial cysts of the pineal gland: a report of seven cases and review of the literature. J Neurol Neurosurg Psychiatry 1989; 52: 991-995.

22. Fain JS, Tomlinson FH, Scheithauer BW, et al. Symptomatic glial cysts of the pineal gland. J Neurosurg 1994; 80: 454-460.

23. Pussep L. Die operative Entfernung einer Zyste der Glandula pinealis. Neurol Zentralbl 1914; 33: 560-563.

24. Sevitt S, Schorstein J. A case of pineal cyst. BMJ 1947; 2: 490-491.

25. Kabuto M, Hayashi M, Kawano H. A case of non-neoplastic pineal cyst presenting as Parinaud's syndrome. No Shinkei Geka 1987; 15: $335-338$
26. Vaquero J, Martinez M, Escanden J, Bravo G. Symptomatic glial cysts of the pineal gland. Surg Neurol 1988; 30: 468-470.

27. Maurer PK, Ecklund J, Parisi JE, Ondra S. Symptomatic pineal cysts: case report. Neurosurgery 1990; 27: 451-454.

28. Todo T, Kndo T, Shinoura N, Yamada R. Large cysts of the pineal gland: report of two cases. Neurosurgery 1991; 29: 101-106.

29. Oeckler R, Feiden W. Benign symptomatic lesions of the pineal gland. Report of seven cases treated surgically. Acta Neurochirg (Wien) 1991; 108: 40-44.

30. Stern JD, Ross DA. Stereotactic management of benign pineal region cysts: report of two cases. Neurosurgery 1993; 32: 310314.

31. Musolino A, Cambria S, Rizzo G, Cambria M. Symptomatic cysts of the pineal gland: stereotactic diagnosis and treatment of two cases and review of the literature. Neurosurgery 1993; 32: 315-321.

32. Turtz AR, Hughes WB, Goldman WH. Endoscopic treatment of a symptomatic pineal cyst: technical case report. Neurosurgery 1995; 37(5): 1013-1015.

33. Milroy CM, Smith CI. Sudden death due to a glial cyst of the pineal gland. J Clin Pathol 1996; 49: 267-269.

34. Di Chirico A, Di Rocco F, Velardi F. Spontaneous regression of a symptomatic pineal cyst after endoscopic third-ventriculostomy. Child's Nerv Syst 2001; 17: 42-46.

35. Kang HS, Kim DG, Han DH. Large glial cyst of the pineal gland: a possible growth mechanism. J Neurosurg 1998; 88: 138-140. 